\title{
WEIGHTED WEAK-TYPE INEQUALITIES FOR SQUARE FUNCTIONS
}

\author{
ADAM OSȨKOWSKI
}

\begin{abstract}
The paper is devoted to weighted weak-type inequalities for square functions of continuous-path martingales and identifies the optimal dependence of the weak norm on the characteristic of the weight. The proof rests on Bellman function technique: the estimates are deduced from the existence of special functions enjoying appropriate size conditions and concavity.
\end{abstract}

Mathematics subject classification (2010): 46E30, 60G42.

Keywords and phrases: Square function, weight, Bellman function.

\section{REFERENCES}

[1] R. BAÑUELOS AND A. OsȨKOWSKI, Weighted norm inequalities for fractional maximal operators a Bellman function approach, Indiana Math. J. 64 (2015), 957-972.

[2] R. BAÑUElos AND A. OsȩKowsKi, Sharp Weighted $L^{2}$ inequalities for square functions, Trans. Amer. Math. Soc. 370 (2018), pp. 2391-2422.

[3] R. Bañuelos AND A. OsȨKowsKi, Weighted square function estimates, to appear in Bull. Sci. Math.

[4] S. M. BUCKLEY, Estimates for operator norms on weighted spaces and reverse Jensen inequalities, Trans. Amer. Math. Soc. 340 (1993), 253-272.

[5] C. Dellacherie And P.-A. Meyer, Probabilities and potential B: Theory of martingales, North Holland, Amsterdam, 1982.

[6] C. Domingo-Salazar, M. LaCEy And G. Rey, Borderline weak-type estimates for singular integrals and square functions, Bull. London Math. Soc. 48 (2016), 63-73.

[7] T. HYTÖNEN, The sharp weighted bound for general Calderón-Zygmund operators, Ann. Math. 175 (2012), 1473-1506.

[8] T. HYTÖNEN AND K. LI, Weak and strong $A_{p}-A_{\infty}$ estimates for square functions and related operators, Proc. Amer. Math. Soc. 146 (2018), 2497-2507.

[9] M. IZUMISAWA AND N. KAZAMAKI, Weighted norm inequalities for martingales, Tôhoku Math. Journ. 29 (1977), 115-124.

[10] M. T. Lacey, K. Moen, C. Pérez and R. H. Torres, Sharp weighted bounds for fractional integral operators, J. Funct. Anal. 259 (2010), pp. 1073-1097.

[11] A. LERNER, Sharp weighted norm inequalities for Littlewood-Paley operators and singular integrals, Adv. Math., 226 (2011), 3912-3926.

[12] B. Muckenhoupt, Weighted norm inequalities for the Hardy maximal function, Trans. Amer. Math. Soc 165 (1972), 207-226.

[13] F. Nazarov, A. Reznikov, S. Treil and A. Volberg, A Bellman function proof of the $L^{2}$ bump conjecture, J. Anal. Math. 121 (2013), 255-277.

[14] F. NAZAROV AND S. TREIL, The hunt for a Bellman function: applications to estimates for singular integral operators and to other classical problems of harmonic analysis, St. Petersburg Math. J. 8 (1997), 721-824.

[15] F. Nazarov, S. Treil And A. Volberg, The Bellman functions and two-weight inequalities for Haar multipliers, J. Amer. Math. Soc., 12 (1999), pp. 909-928.

[16] A. OsȨKows KI, Weighted Inequalities for the Dyadic Square Function, Integral Equations and Operator Theory 85 (2016), pp. 359-380. 
[17] A. OsȨKOWSKI, Weighted inequalities for martingale transforms and stochastic integrals, Mathematika 63 (2017), 433-450.

[18] G. PES KIR, A Change-of-Variable Formula with Local Time on Surfaces, In: Donati-Martin C., Émery M., Rouault A., Stricker C. (eds) Séminaire de Probabilités XL. Lecture Notes in Mathematics, vol 1899. Springer, Berlin, Heidelberg, 2007.

[19] V. VASYUNIN, The exact constant in the inverse Hölder inequality for Muckenhoupt weights (Russian), Algebra i Analiz 15 (2003), 73-117; translation in St. Petersburg Math. J. 15 (2004), pp. 49-79.

[20] G. WANG, Differential subordination and strong differential subordination for continuous-time martingales and related sharp inequalities, Ann. Probab. 23 (1995), no. 2, 522-551.

[21] J. WITTwER, A sharp bound for the martingale transform, Math. Res. Lett. 7 (2000), 1-12. 